\title{
A diet based on multiple functional concepts improves cardiometabolic risk parameters in healthy subjects
}

Juscelino Tovar ${ }^{1 *}$, Anne Nilsson², Maria Johansson ${ }^{1}$, Rickard Ekesbo ${ }^{3}$, Ann-Margreth Åberg ${ }^{3}$, Ulla Johansson ${ }^{4}$ and Inger Björck ${ }^{1,2}$

\begin{abstract}
Background: Different foods can modulate cardiometabolic risk factors in persons already affected by metabolic alterations. The objective of this study was to assess, in healthy overweight individuals, the impact of a diet combining multiple functional concepts on risk markers associated with cardiometabolic diseases (CMD).

Methods: Fourty-four healthy women and men (50-73 y.o, BMI 25-33, fasting glycemia $\leq 6.1$ mmol/L) participated in a randomized crossover intervention comparing a multifunctional (active) diet (AD) with a control diet (CD) devoid of the "active" components. Each diet was consumed during 4 wk with a 4 wk washout period. AD included the following functional concepts: low glycemic impact meals, antioxidant-rich foods, oily fish as source of long-chain omega-3 fatty acids, viscous dietary fibers, soybean and whole barley kernel products, almonds, stanols and a probiotic strain (Lactobacillus plantarum Heal19/DSM15313).
\end{abstract}

Results: Although the aim was to improve metabolic markers without promoting body weight loss, minor weight reductions were observed with both diets $(0.9-1.8 \pm 0.2 \%$; $P<0.05)$. $C D$ did not modify the metabolic variables measured. AD promoted significant changes in total serum cholesterol ( $-26 \pm 1 \%$ vs baseline; $P<0.0001)$, LDLcholesterol $(-34 \pm 1 \% ; P<0.0001)$, triglycerides $(-19 \pm 3 \% ; P=0.0056)$, LDL/HDL $(-27 \pm 2 \% ; P<0.0001)$, apoB/ apoA1 $(-10 \pm 2 \% ; P<0.0001), H_{b A}(-2 \pm 0.4 \% ; P=0.0013)$, hs-CRP $(-29 \pm 9 \% ; P=0.0497)$ and systolic blood pressure $(-8 \pm 1 \%, P=0.0123)$. The differences remained significant after adjustment for weight change. After $A D$, the Framingham cardiovascular risk estimate was $30 \pm 4 \%(P<0.0001)$ lower and the Reynolds cardiovascular risk score, which considers CRP values, decreased by $35 \pm 3 \%(P<0.0001)$.

Conclusion: The improved biomarker levels recorded in healthy individuals following the multifunctional regime suggest preventive potential of this dietary approach against CMD.

Keywords: Cardiometabolic disease, metabolic syndrome, dietary prevention, functional foods, randomized controlled trial, crossover design

\section{Background}

Cardiometabolic diseases (CMD), i.e. cardiovascular disease and diabetes mellitus, are important causes of morbidity and mortality worldwide [1]. Therefore, any person with multiple cardiometabolic risk factors would benefit from lifestyle changes, including improvement of dietary habits, to favorably modify as many as possible

\footnotetext{
* Correspondence: Juscelino.Tovar@ffsc.lu.se

'Antidiabetic Food Centre, Lund University, P.O. Box 121, SE-221 00 Lund, Sweden

Full list of author information is available at the end of the article
}

risk-associated features [2]. Current recommendations for dietary management of subjects with high metabolic risk involve quantitative and qualitative changes in fat and sugar intakes and high consumption of fruits, vegetables, and whole grains [3]. These guidelines focus on lowering LDL cholesterol, fasting glycemia, body weight and blood pressure as a way to reduce the risk of heart disease $[2,3]$. In this context, a portfolio of vegetarian foods has been shown capable of improving LDL cholesterol, HDL cholesterol and CRP values in hypercholesterolemic subjects [4-7]. Similarly, a Nordic-type diet
C Biomed Central

C 2012 Tovar et al; licensee BioMed Central Ltd. This is an Open Access article distributed under the terms of the Creative Commons Attribution License (http://creativecommons.org/licenses/by/2.0), which permits unrestricted use, distribution, and reproduction in any medium, provided the original work is properly cited. 
can modulate the blood lipid profile of hypercholesterolemics [8].

However, a more comprehensive approach to the dietary prevention of CMD also requires attention to other risk factors besides altered blood lipids or glycemia. An increasing number of studies show that different functional foods and ingredients $[9,10]$ may exert positive effects on particular parameters related to the metabolic syndrome (MetS), a cluster of pathophysiologic conditions increasing cardiometabolic risk [11-13]. Such observations may provide the basis for an effective preventive dietary strategy, in which the inclusion of an ample spectrum of active food components or properties may decrease multiple risk factors. The present investigation explores the CMD preventive potential of a diet based on a combination of functional concepts, chosen on the basis of their beneficial effects on single metabolic risk markers.

Since subclinical chronic inflammation is considered an important factor in the etiology of CMD and MetS $[2,12,13]$, the components of the multifunctional "active" diet (AD) were selected mainly for their perceived abilities to reduce inflammatory tonus. Within this frame, AD included low glycemic impact foods/meals, foods naturally rich in antioxidant polyphenols and fish products rich in omega-3 fatty acids [14-17]. Moreover, the active diet also contained a probiotic Lactobacillus strain capable to decrease the inflammatory response in an animal model [18] and an important supply of soluble dietary fiber from barley and oat, with suggested prebiotic antiinflammatory action in humans [19-21]. Another functional concept encompassed in the diet corresponds to foods and ingredients with recognized blood lipidmodulating actions, cholesterol lowering items in particular $[2,4]$.

We hypothesized that a combination of the above food concepts may target sub-clinical inflammation in a synergistic way and thus allow for the prescription of practically feasible intakes of the active foods. The study was performed in a healthy middle-aged group of overweight volunteers, comparing the AD vs. a control diet (CD) using a cross-over design, with 4-wk study periods. The aim was to improve cardiometabolic risk-associated parameters by changing dietary composition without promoting weight loss.

\section{Participants and methods Participants}

Volunteers without any known medical condition (36 females, $8 \mathrm{men}$ ) were recruited through advertisement in local newspapers and were informed orally and in writing of the project disposal, emphasizing the non weight-loss character of the investigation. Inclusion criteria were age between 50 and 73 , body mass index in the $25-33 \mathrm{~kg} / \mathrm{m}^{2}$ range and fasting plasma glucose value $\leq 6.1 \mathrm{mmol} / \mathrm{L}$. Only medications accepted were hormone replacement for thyroid problems (if constant during the whole trial; 1 female subject) and prescription-free painkillers without antinflammatory action. Baseline data collected at the time of the first clinical visit are shown in Table 1.

\section{Study Protocol}

The study was designed as a randomized, controlled, crossover trial of the effect of a multifunctional $\mathrm{AD}$ on markers related to cardiometabolic risk. Participants were randomly assigned to one of two treatment orders starting with the $\mathrm{AD}$ or the $\mathrm{CD}$, respectively. Each diet phase lasted 4 wk with a 4 -wk washout period. The whole trial included four clinical visits, one before and one after each intervention period. During the first visit the participants underwent a physical examination, including auscultation of heart and lungs.

On each clinical visit, fasting body weight was recorded and BP was measured twice, while seating, in the non-dominant arm with a mercury

Table 1 Characteristics of participants at baseline ${ }^{a}$

\begin{tabular}{|c|c|c|c|}
\hline & $\begin{array}{l}\text { Whole group } \\
(\mathrm{n}=44)\end{array}$ & $\begin{array}{l}\text { Females } \\
(\mathrm{n}=36)^{\mathrm{b}}\end{array}$ & $\begin{array}{l}\text { Males } \\
(\mathrm{n}=8)\end{array}$ \\
\hline Age (y) & $63.3 \pm 0.8$ & $63.2 \pm 0.8$ & $63.6 \pm 1.9$ \\
\hline Body weight (kg) & $79.4 \pm 1.4$ & $77.4 \pm 1.9$ & $88.6 \pm 2.5$ \\
\hline BMI $\left(\mathrm{kg} / \mathrm{m}^{2}\right)$ & $28.5 \pm 0.3$ & $28.5 \pm 0.4$ & $28.3 \pm 0.3$ \\
\hline \multicolumn{4}{|l|}{ Cholesterol (mmol/L) } \\
\hline Total & $5.75 \pm 0.16$ & $5.79 \pm 0.16$ & $5.55 \pm 0.25$ \\
\hline $\mathrm{LDL}$ & $3.65 \pm 0.15$ & $3.64 \pm 0.80$ & $3.68 \pm 0.40$ \\
\hline $\mathrm{HDL}$ & $1.54 \pm 0.05$ & $1.62 \pm 0.06$ & $1.20 \pm 0.01$ \\
\hline Triacylglycerols (mmol/L) & $1.33 \pm 0.11$ & $1.17 \pm 0.05$ & $2.09 \pm 0.20$ \\
\hline \multicolumn{4}{|l|}{ Apolipoproteins (g/L) } \\
\hline Apo A-1 & $1.64 \pm 0.03$ & $1.68 \pm 0.04$ & $1.42 \pm 0.07$ \\
\hline Apo B & $0.96 \pm 0.04$ & $0.96 \pm 0.02$ & $0.96 \pm 0.11$ \\
\hline Insulin (mU/L) & $6.75 \pm 0.66$ & $6.06 \pm 0.21$ & $9.87 \pm 0.01$ \\
\hline Glucose $(\mathrm{mmol} / \mathrm{L})$ & $5.20 \pm 0.06$ & $5.18 \pm 0.11$ & $5.32 \pm 0.03$ \\
\hline HOMA-IR & $1.41 \pm 0.15$ & $1.25 \pm 0.07$ & $2.16 \pm 0.01$ \\
\hline $\mathrm{HbA}_{1 \mathrm{c}}(\%)$ & $4.58 \pm 0.05$ & $4.59 \pm 0.03$ & $4.53 \pm 0.05$ \\
\hline Free fatty acids (mmol/L) & $0.39 \pm 0.02$ & $0.41 \pm 0.07$ & $0.35 \pm 0.05$ \\
\hline CRP (mg/L) & $2.58 \pm 0.34$ & $2.79 \pm 0.22$ & $1.61 \pm 0.15$ \\
\hline IL-6 (ng/L) & $0.82 \pm 0.07$ & $0.82 \pm 0.03$ & $0.81 \pm 0.13$ \\
\hline TNF- $\alpha$ (ng/L) & $10.51 \pm 0.36$ & $10.55 \pm 0.35$ & $10.38 \pm 2.00$ \\
\hline PAl-1 (U/mL) & $24.56 \pm 2.28$ & $22.83 \pm 0.31$ & $30.63 \pm 2.67$ \\
\hline \multicolumn{4}{|l|}{ Blood Pressure $(\mathrm{mm} \mathrm{Hg})$} \\
\hline Systolic & $138.5 \pm 2.8$ & $139.1 \pm 4.0$ & $136.3 \pm 1.2$ \\
\hline Diastolic & $80.3 \pm 1.3$ & $80.5 \pm 2.0$ & $79.8 \pm 7.5$ \\
\hline
\end{tabular}

avalues are means \pm SEM

${ }^{\mathrm{b}}$ Thirty-five post-menopausal, 1 peri-menopausal. 
sphyngomanometer. Venous blood was then drawn for the assessment of fasting blood glucose, insulin, HbA1c, cholesterol (total, LDL and HDL), triglycerides, high sensitivity CRP (hs-CRP), PAI-1, IL-6, TNF- $\alpha$, FFA, apo A1, apo B.

Consumption of dietary supplements such as fish oil (9 subjects), probiotic-containing products (11 subjects) and herbal extracts (11 subjects), was stopped 2 weeks before the start of the trial. Before each dietary phase, the participants attended an introductory session with the nutritionist, who explained practical details of the upcoming diet period.

Volunteers were asked to maintain their normal physical activity regime during the study. A pretrial questionnaire indicated that $48 \%$ of the subjects had physical activity equivalent to $1 \mathrm{~h}$ /day or more, 30\% had 30-60 $\mathrm{min} /$ day and $22 \%$ reported a low activity level $(<30$ $\mathrm{min} /$ day). Subjects were also instructed to record their fasting body weight weekly. Variations larger than $1 \mathrm{Kg}$ were reported to the nutritionist, who suggested compensatory dietary modifications. The intake of key components in $\mathrm{AD}$ was not affected by these modifications.

Except for almonds and fresh, frozen and smoked fish, the active food items required for the 4-wk AD were provided. Some of the foods included in the CD were also provided. In order to assess dietary compliance, participants completed a daily menu checklist covering each 4-wk diet period. They also completed a questionnaire investigating their experience with each diet. Coaching support was provided by the nutritionist, who contacted each participant at least once per diet period. The study was approved by the Regional Ethical Review Board, Lund, Sweden (Dnr 593/2008).

\section{Diets}

Participants ate their habitual diet before and between the experimental periods. A dietary habit questionnaire completed before randomization to the starting dietary treatment was used to help the participants to resume their eating habits during the washout period. To ensure good compliance the participants were provided with a detailed 2-wk rotating menu plan for each dietary period (AD and $C D$ ) with all foods ingredients expressed in weight and/or volume measures. Electronic self-taring scales were made available whenever needed. The menu plan also included recipes for preparing meals.

The nutritional profiles of $\mathrm{CD}$ and $\mathrm{AD}$ are shown in Table 2. Both diets were designed in close agreement with the Nordic Nutrition Recommendations [22] and supplied 2,500-2,600 Kcal/d for men and 2,000-2,100 $\mathrm{Kcal} / \mathrm{d}$ for women, combining foods from plant and animal origin. Both diets incorporated commercial foods available in food stores, but the AD also included
Table 2 Nutritional profile of CD and AD

\begin{tabular}{lllll}
\hline & \multicolumn{2}{c}{ Control Diet } & \multicolumn{2}{c}{ Active Diet } \\
\cline { 2 - 5 } & Women & Men & Women & Men \\
Energy (kcal/day)* & 2045 & 2570 & 2100 & 2615 \\
Protein (E\%) & 15 & 14 & 19 & 18 \\
Carbohydrate (E\%) & 56 & 55 & 51 & 50 \\
Fat (E\%) & 29 & 30 & 31 & 31 \\
Saturated fat (E\%) & 12.8 & 13.2 & 5.9 & 5.9 \\
Monounsaturated fat (E\%) & 10.5 & 11.1 & 13.0 & 13.6 \\
Polyunsaturated fat (E\%) & 3.6 & 3.7 & 8.2 & 8.4 \\
$\omega$-6 fatty acids (E\%) & 2.9 & 3.1 & 4.2 & 4.3 \\
$\omega$-3 fatty acids (E\%) & 0.8 & 0.8 & 2.2 & 2.3 \\
$\omega$-6/ $\omega$-3 ratio & 3.8 & 3.8 & 1.9 & 1.9 \\
Dietary fiber (g/day) & 22 & 26 & 49 & 61 \\
Cholesterol (mg/day) & 200 & 240 & 140 & 160 \\
\hline
\end{tabular}

* Increased energy intake was prescribed for subjects that experienced weight loss during the initial weeks (see Study Protocol section)

prototypes. For a detailed list of products included in AD see additional file 1 .

AD combined several functional concepts with potential to modulate different physiological variables related to the inflammatory tonus and cardiometabolic risk, including:

a) food items naturally rich in antioxidants which, in addition to the anti-inflammatory action of their antioxidants [16], contain phenolics that may improve BP and blood lipids [23-25].

b) omega-3 fatty acids, especially those long-chained present in oily fish, which have antiinflammatory and triglyceride-lowering properties $[17,26]$. In addition, the overall fat quality was also a concept included in the diet design. Thus, the unsaturated-to-saturated fat ratio was larger in $\mathrm{AD}$ than in $\mathrm{CD}$ (3.6 vs 1.2, respectively; Table 2).

c) ingredients with potential to beneficially affect the gut microbiota: a probiotic strain (Lactobacillus plantarum Heal19, DSM 15313) [18], and prebiotics, i.e. beta-glucans and resistant starch $[19,20]$ in intact barley kernels, whole kernel rye flour and isolated barley fiber, which were used for baking an experimental beta-glucan-rich bread. Additional sources of viscous fermentable dietary fibre were a prototype oat-based fiber drink, a rye/oat breakfast cereal and an oat-based muesli.

d) low glycemic impact foods/meals were included for their association with reduced risk for the MetS [27] and Type- 2 diabetes [28], and its perceived ability to ameliorate the inflammatory tonus in healthy individuals [29]. Low GI foods were represented by products with high beta-glucan content which, besides their prebiotic role, may improve glycemic regulation in a 10 -h postingestion perspective, through mechanisms related to colonic fermentation and lowered inflammatory tonus 
$[20,21]$. AD also included another high-fibre bread, baked from a wheat flour/guar gum blend: This item promotes a low glycemic response, with reduced peak and prolonged duration of net increment above fasting glucose levels (A. Nilsson, K. Radeborg et al., unpublished results). Additionally, AD included ingredients that lower the post-meal glycemic excursion, such as whey protein and vinegar $[14,15]$.

e) ingredients with acknowledged abilities to normalize blood levels of both total and LDL cholesterol were also provided: different soybean products, a margarine enriched in stanol esters and dry almonds [4,12,30-32].

The mean daily quantities of the different functional ingredients in $\mathrm{AD}$ and the main functional properties considered for their selection are summarized in Table 3 . None of the active ingredients were included in the $\mathrm{CD}$, except for minor amounts of $\omega-3$ fatty acids.

Participants were provided with a 14-day rotating menu plan. For representative 1-day menu plans for the $\mathrm{CD}$ and $\mathrm{AD}$ see additional file 2. A limited amount of alcohol-containing drinks were allowed during both dietary periods (30 and $37 \mathrm{~g}$ ethanol/wk for women and men, respectively). These limits, however, did not compel low-drinkers to increase their habitual alcohol consumption. Due to the low overall energy contribution from such contingent alcoholic drinks, they were not included in the estimation of the energy content of diets. The volunteers' coffee and tea drinking habits were not modified during the trial.

\section{Analyses}

Routine blood tests were analyzed at the Clinical Chemistry Laboratory/Skåne University Hospital Lund, on fasting plasma (total and HDL cholesterol, triacylglycerols, apo A-1, apo B, high-sensitivity C-reactive protein), serum (insulin) or on total blood samples (HbA1c). LDL cholesterol concentrations were calculated [39]. HOMAIR was calculated from fasting blood plasma-glucose and serum insulin values [40].

Venous plasma glucose concentrations were measured immediately after bleeding (HemoCue ${ }^{\circledR} \mathrm{B}$-glucose, HemoCueAB, Ängelholm, Sweden). Serum concentrations of TNF- $\alpha$ and IL- 6 were measured with a chemiluminescent immunometric assay, Immulite ${ }^{\circledR} /$ Immulite $^{\circledR}$ 1000 TNF- $\alpha$ (Siemens, Deerfield, IL, USA) and a sensitive enzyme-linked immunosorbent assay, Quantikine ${ }^{\circledR}$ HS (RD Systems Inc, Abingdon, UK), respectively. Samples with high IL-6 concentration (>10 ng/L) in the ELISA were also measured with the Immulite ${ }^{\circledR} /$ Immulite ${ }^{\circledR} 1000$ IL- 6 assay (Siemens, Deerfield, IL, USA). Serum FFA were assessed with an enzymatic colorimetric assay kit (Wako Chemicals $\mathrm{GmbH}$, Germany). Plasminogen activator inhibitor (PAI-1) activity in plasma was measured with TriniLize PAI-1 Activity kit (Trinity Biotech, Jamestown NJ, USA).

The diet compositions were analyzed using the 2009 food database from the Swedish National Food Administration and a computerized calculation program (Dietist XP 3.1; Kost och Näringsdata AB, Bromma, Sweden).

Table 3 Proposed functional action, previously tested dose and actual average content of active components in the active diet

\begin{tabular}{|c|c|c|c|c|c|}
\hline & \multirow[t]{2}{*}{$\begin{array}{l}\text { Main functional } \\
\text { role }\end{array}$} & \multirow[t]{2}{*}{$\begin{array}{l}\text { Previously tested dose (g/ } \\
\text { day) }\end{array}$} & \multirow[t]{2}{*}{ References } & \multicolumn{2}{|c|}{$\begin{array}{c}\text { Content in the } A D \\
\text { (g/day) }\end{array}$} \\
\hline & & & & Women & Men \\
\hline Soybean/soy protein & Cholesterol-lowering, anti-inflammatory & $25-47$ & {$[4,30,33-35]$} & 21 & 25 \\
\hline Viscous fibers & $\begin{array}{l}\text { Cholesterol- lowering, prebiotic, Gl- } \\
\text { reducing }\end{array}$ & $10-25$ & {$[12,19]$} & & \\
\hline$\beta$-glucans & & & & 5.8 & 6.2 \\
\hline Guar gum & & & & 5.6 & 6.7 \\
\hline Total & & & & 11.4 & 12.9 \\
\hline $\begin{array}{l}\text { Long chain } \omega-3 \text { fatty acids (20:5 + } \\
22: 6)\end{array}$ & Triglyceride-lowering, anti-inflammatory & $2-6$ & {$[17,26]$} & 2.4 & 3.0 \\
\hline Almonds & Cholesterol-lowering & $28-100$ & {$[4,32]$} & 28 & 28 \\
\hline Plant stanols & Cholesterol-lowering & $2-3$ & {$[4,31]$} & 2.0 & 2.7 \\
\hline Cinnamon & Antioxidant & 6 & [25] & 3.0 & 3.0 \\
\hline Blueberries & Antioxidant, prebiotic & 350 & {$[36]$} & 74.5 & 94.5 \\
\hline Vinegar & Gl -reducing & 20 & [14] & 22.5 & 22.5 \\
\hline Probiotic & Cholesterol-lowering, anti-inflammatory & $10^{10} \mathrm{CFU}$ & {$[18,37,38]$} & $\begin{array}{l}0.1 \\
\left(10^{10}\right. \\
\text { CFU) }\end{array}$ & $\begin{array}{l}0.1 \\
\left(10^{10}\right. \\
\text { CFU) }\end{array}$ \\
\hline Whey protein* & Gl-reducing & 10 & [15] & 4.3 & 4.3 \\
\hline
\end{tabular}

*Whey protein $(10 \mathrm{~g})$ was only consumed simultaneously with high glycemic index meals (potatoes, parsnip), 3 times per week. 


\section{Calculations and statistical analysis}

The results are expressed as means \pm SEM. Data were evaluated by mixed model ANOVA with sequence and interaction between diet and start/end of treatment periods as fixed effects, and participants within sequence and visit as random effects. Least square means were estimated for the start (Active-week 0, Control-week 0) and end values (Active-wk 4, Control-wk 4) for each diet. Least square means and confidence intervals were calculated for the differences between Active/wk 0, Control/wk 0, Active/wk 4 and Control/wk 4, as well as for the net difference between the diets, i.e. (Active/wk 4 Active/wk 0) - (Control/wk 4 - Control/wk 0). Another set of analyses with body weight included as a continuous covariate was performed. Analyses were carried out using SAS PROC Mixed (v. 8.2, SAS Institute Inc., Cary, NC, USA). Ten-year coronary heart disease risk was calculated both with the Framingham Study equation [41] considering age, gender, total cholesterol, HDL-cholesterol, smoking and systolic BP values, and the Reynolds Risk Score [42,43], which also incorporates CRP values.

\section{Power calculation}

Primary outcome measure was change in plasma LDL cholesterol. Assuming a $0.5 \mathrm{mmol} / \mathrm{L}$ (approximately $10 \%)$ post-diet difference and a $0.97 \mathrm{SD}$ [44], with $\alpha=$ 0.05 and $1-\beta=0.8$, a minimum of 30 participants were required. Among additional measures, changes in hsCRP were also taken into account. Assuming a $0.44 \mathrm{mg} /$ L (10\%) post-diet difference and a SD of 1.0 [45], the required sample size was 42 subjects. Data obtained from hypercholesterolemics with normal CRP levels [7] confirmed that this $n$ value provides sufficient power for assessing CRP changes.

\section{Results}

\section{Study population and dietary compliance}

Recruitment began February 2009. Trials took place between March 2009 and February 2010. Forty-six volunteers enrolled in the study. The volunteers came from different towns and rural areas in Southwestern Sweden. One participant dropped out during the first week. Forty-five completed the two phases of the intervention. One completer declared to have suffered a minor cerebro-vascular incident some years ago and was therefore excluded from the evaluation. Results from 44 completers ( 36 women and 8 men) aged 51 - 73 (mean 63.3) were analysed. Only 2 subjects were smokers.

Baseline data confirmed the healthy condition of the cohort studied. This was also evident from the fact that 26 out of the 44 completers (i.e. 59\%) showed none of the MetS features assessed (total cholesterol $>150 \mathrm{mg}$ / $\mathrm{dL}, \mathrm{BP}>130 / 85 \mathrm{~mm} \mathrm{Hg}$ and HDL-cholesterol $<50 \mathrm{mg} /$ dL) [46].
Adherence to the dietary plan was good, with similar compliance $(P=0.07)$ for AD $(92 \pm 2 \%)$ and CD $(89 \pm$ $5 \%)$. No major problem to consume the prescribed foods was reported. Fifty percent of the participants described $\mathrm{AD}$ as more satiating than their habitual diet and 25\% expressed that sensation for CD. Ninety percent of the participants experienced increased intestinal gas production with $\mathrm{AD}$ as compared to their regular regimes; however, only five participants (11\%) qualified this as a burden.

\section{Body weight}

Despite the dietary advice provided, weight losses were registered after $\mathrm{CD}(-0.9 \%)$ and $\mathrm{AD}(-1.8 \%)$ (Table 4$)$. Although final body weight was similar with the two treatments, there was a significant difference between diets $(P=0.0113)$ (Table 4$)$.

\section{Blood lipids and lipoproteins}

AD reduced total cholesterol $(P<0.0001)$, LDL cholesterol $(P<0.0001)$ and triglycerides $(P=0.0004)$ by $26 \%$, $24 \%$ and $19 \%$, respectively, while no change was recorded after the CD period (Table 4). The difference between the two dietary treatments remained after correction for body weight reduction $(P<0.0001, P<$ 0.0001 and $P=0.0011$, respectively; Table 4 ).

HDL-cholesterol values were similarly reduced by both diets $(P=0.01635)$ but AD improved both the LDL/ HDL ratio (from 2.51 to 1.83 , ie. $-27 \%, P<0.0001$ ) and ApoB to ApoA-1 ratio (from 0.59 to $0.53 ;-10 \%$; $P<$ $0.0001)$. The difference between diets was significant $(P$ $<0.0001$ ) after correction for weight changes (Table 4).

\section{Glycemic control variables}

No difference in the effect on fasting insulin concentrations was recorded between $\mathrm{AD}$ and $\mathrm{CD}(P=0.9410)$, although AD promoted a significant $(P=0.0436)$ reduction from baseline (Table 4). AD increased fasting blood glucose levels by $6 \%$, with a significant difference between diets after correction for weight changes $(P=0.0002$; Table 4). None of the diets affected HOMA-IR values or fasting FFA levels. A $2 \%$ decrease in HbA1c was detected after $\mathrm{AD}$, an effect that remained significant after correction for body weight variation $(P=0.0013$; Table 4$)$.

\section{Blood pressure}

Systolic BP was $8 \%$ lower after AD whereas CD had no effect. The difference between diets remained significant after weight correction $(P=0.0134$; Table 4$)$. Diastolic pressure values were not affected by any of the diets (Table 4).

\section{Inflammatory and pro-thrombotic status markers}

AD reduced hs-CRP value by $29 \%$, with no effect for CD (Table 5). The difference between diets was significant 
Table 4 Effect of CD and AD on plasma lipids, parameters of insulin sensitivity and blood pressure ${ }^{a}$

\begin{tabular}{|c|c|c|c|c|c|c|c|c|}
\hline & \multicolumn{3}{|c|}{ Control Diet } & \multicolumn{3}{|c|}{ Active Diet } & \multirow[b]{2}{*}{$P(A-C)^{b}$} & \multirow[b]{2}{*}{$P(\mathrm{~A}-\mathrm{C} ;$ weight corrected) } \\
\hline & Week 0 & Week 4 & Change (\%) & Week 0 & Week 4 & Change (\%) & & \\
\hline Body weight $(\mathrm{kg})^{\mathrm{d}}$ & $78.9 \pm 1.7$ & $78.2 \pm 1.34^{h}$ & -0.9 & $79.4 \pm 1.36^{i}$ & $78.0 \pm 1.30^{f}$ & -1.8 & 0.0113 & \\
\hline \multicolumn{9}{|l|}{ Cholesterol (mmol/L) } \\
\hline Total $^{\mathrm{d}}$ & $5.73 \pm 0.16$ & $5.79 \pm 1.39$ & 1 & $5.81 \pm 0.17$ & $4.29 \pm 0.10^{f}$ & -26 & $<0.0001$ & $<0.0001$ \\
\hline $\operatorname{LDL}^{\mathrm{d}}$ & $3.66 \pm 0.15$ & $3.70 \pm 0.16$ & 1 & $3.65 \pm 0.16$ & $2.42 \pm 0.10^{f}$ & -34 & $<0.0001$ & $<0.0001$ \\
\hline$H D L^{e}$ & $1.53 \pm 0.04$ & $1.43 \pm 0.04^{h}$ & -7 & $1.54 \pm 0.05$ & $1.39 \pm 0.04^{9}$ & -10 & 0.1637 & 0.1501 \\
\hline Triglycerides $(\mathrm{mmol} / \mathrm{L})^{d}$ & $1.36 \pm 0.11$ & $1.38 \pm 0.62$ & 1 & $1.32 \pm 0.09$ & $1.07 \pm 0.06^{9}$ & -19 & 0.0056 & 0.0011 \\
\hline \multicolumn{9}{|l|}{ Apolipoproteins (g/L) } \\
\hline Apo $A-1^{d}$ & $1.62 \pm 0.03$ & $1.54 \pm 0.03^{f}$ & 5 & $1.62 \pm 0.04$ & $1.40 \pm 0.02^{f}$ & -14 & $<0.0001$ & $<0.0001$ \\
\hline$A p o B^{d}$ & $0.95 \pm 0.04$ & $0.95 \pm 0.03$ & 0 & $0.94 \pm 0.04$ & $0.72 \pm 0.02^{f}$ & -23 & $<0.0001$ & $<0.0001$ \\
\hline \multicolumn{9}{|l|}{ Ratios } \\
\hline $\mathrm{LDL} / \mathrm{HDL}^{\mathrm{d}}$ & $2.53 \pm 0.03$ & $2.73 \pm 0.03^{h}$ & 8 & $2.51 \pm 0.02$ & $1.83 \pm 0.03^{f}$ & -27 & $<0.0001$ & $<0.0001$ \\
\hline ApoB/ApoA-1 ${ }^{d}$ & $0.60 \pm 0.03$ & $0.63 \pm 0.03$ & 5 & $0.59 \pm 0.03$ & $0.53 \pm 0.02^{f}$ & -10 & $<0.0001$ & $<0.0001$ \\
\hline Insulin $(\mathrm{mU} / \mathrm{L})^{\mathrm{e}}$ & $6.70 \pm 0.42$ & $5.70 \pm 0.25$ & -14 & $6.08 \pm 0.42$ & $5.03 \pm 0.36^{h}$ & -17 & 0.9410 & 0.9826 \\
\hline Glucose $(\mathrm{mmol} / \mathrm{L})^{\mathrm{d}}$ & $5.21 \pm 0.07$ & $5.13 \pm 0.07$ & -1 & $5.17 \pm 0.07$ & $5.46 \pm 0.08^{9}$ & 6 & 0.0002 & 0.0002 \\
\hline HOMA-IR & $1.39 \pm 0.08$ & $1.17 \pm 0.08$ & -16 & $1.26 \pm 0.09$ & $1.09 \pm 0.06$ & -14 & 0.7376 & 0.6983 \\
\hline $\mathrm{HbA}_{1 \mathrm{c}}(\%)^{\mathrm{d}}$ & $4.56 \pm 0.05$ & $4.58 \pm 0.05$ & 1 & $4.55 \pm 0.05$ & $4.47 \pm 0.05^{h}$ & -2 & 0.0007 & 0.0013 \\
\hline Free fatty acids (mmol/L) & $0.37 \pm 0.02$ & $0.37 \pm 0.02$ & 0 & $0.37 \pm 0.02$ & $0.37 \pm 0.03$ & 0 & 0.9673 & 0.9627 \\
\hline \multicolumn{9}{|l|}{ Blood pressure (mm Hg) } \\
\hline Systolic & $135 \pm 2$ & $132 \pm 2$ & -2 & $136 \pm 2$ & $128 \pm 2^{f}$ & -8 & 0.0123 & 0.0134 \\
\hline Diastolic & $79 \pm 1$ & $76 \pm 1$ & -4 & $79 \pm 1$ & $76 \pm 1$ & -4 & 0.9984 & 0.9265 \\
\hline
\end{tabular}

${ }^{a}$ Values are means \pm SEM. To convert cholesterol and triglyceride values to $\mathrm{mg} / \mathrm{dL}$, multiply by 38.67 and 88.57 , respectively. To convert apo $\mathrm{A}-1$ and apo $B$ values to $\mathrm{mg} / \mathrm{dL}$, multiply by 100 .

${ }^{\mathrm{b}} P$ value for the comparison of changes after Active diet and Control diet.

${ }^{c} P$ value for the comparison of changes after Active diet and Control diet, after correction for weight change

d, e The overall effect of diet was significant: ${ }^{\mathrm{d}} P<0.001,{ }^{\mathrm{e}} P<0.05$.

f, g, h Significantly different from baseline (Week 0): ${ }^{f} P<0.0001,{ }^{g} p<0.001,{ }^{\mathrm{h}} P<0.05$.

'Active diet baseline (Week 0 ) significantly different from control diet baseline, $P<0.05$.

after correction for body weight reduction $(P=0.0497)$. In spite of a $26 \%$ drop in PAI- 1 after AD, no net difference was registered between the two diets $(P=0.3854)$. None of the diets affected fasting IL- 6 or TNF- $\alpha$ concentrations.

\section{Cardiovascular risk}

Significantly lower overall cardiovascular risk scores were calculated after AD (Table 6). The Framingham Study algorithm indicated a 30-percent risk drop $(P<$
0.0001). The Reynolds risk score predicted a larger risk decline $(35 \% ; P<0.0001)$. The $\mathrm{CD}$ did not reduce risk estimates. The reduction in risk estimates with $\mathrm{AD}$ remained significant after weight correction.

\section{Discussion}

This investigation looked at the possibility of modulating diverse cardiometabolic risk factors by a diet based on multiple functional food concepts. Although a number of therapy-oriented dietary studies have been

Table 5 Effect of CD and AD on circulating inflammatory and thrombotic markers ${ }^{a}$

\begin{tabular}{|c|c|c|c|c|c|c|c|c|}
\hline & \multicolumn{3}{|c|}{ Control Diet } & \multicolumn{3}{|c|}{ Active Diet } & \multirow[b]{2}{*}{$P(\mathrm{~A}-\mathrm{C})^{\mathrm{b}}$} & \multirow[b]{2}{*}{$P(\mathrm{~A}-\mathrm{C} ; \text { weight corrected })^{\mathrm{C}}$} \\
\hline & Week 0 & Week 4 & Change (\%) & Week 0 & Week 4 & Change (\%) & & \\
\hline $\mathrm{CRP}(\mathrm{mg} / \mathrm{L})$ & $2.59 \pm 0.34$ & $2.89 \pm 0.42$ & 12 & $2.79 \pm 0.39$ & $1.99 \pm 0.27^{\mathrm{e}}$ & -29 & 0.0446 & 0.0497 \\
\hline IL-6 (ng/L) & $0.96 \pm 0.09$ & $0.93 \pm 0.09$ & -3 & $0.71 \pm 0.05^{d}$ & $0.81 \pm 0.09$ & 14 & 0.6232 & 0.3807 \\
\hline $\mathrm{TNF}-\alpha(\mathrm{ng} / \mathrm{L})$ & $9.95 \pm 0.36$ & $10.09 \pm 0.45$ & 1 & $11.04 \pm 0.46^{d}$ & $10.38 \pm 0.42$ & -6 & 0.0971 & 0.1094 \\
\hline PAI-1 (U/mL) & $23.34 \pm 1.69$ & $19.33 \pm 1.68$ & -19 & $23.70 \pm 2.17$ & $17.65 \pm 1.47^{e}$ & -26 & 0.3854 & 0.4104 \\
\hline
\end{tabular}

\footnotetext{
aalues are expressed as means \pm SEM.

${ }^{b} P$ value for the comparison of changes after Active diet and Control diet.

${ }^{c} P$ value for the comparison of changes after Active diet and Control diet, after correction for weight change

${ }^{\mathrm{d}}$ Active diet baseline (Week 0 ) significantly different from control diet baseline, $P<0.05$.

${ }^{\text {e}}$ Significantly different from baseline (Week 0$), P<0.05$.
} 
Table 6 Effect of CD and AD on 10-y cardiovascular risk ${ }^{a}$

\begin{tabular}{|c|c|c|c|c|c|c|c|c|}
\hline \multirow[b]{2}{*}{ Calculated 10-y CHD risk (\%) } & \multicolumn{3}{|c|}{ Control Diet } & \multicolumn{3}{|c|}{ Active Diet } & \multirow[t]{2}{*}{$P(\mathrm{~A}-\mathrm{C})^{\mathrm{b}}$} & \multirow[t]{2}{*}{$P(A-C ; \text { weight corrected })^{c}$} \\
\hline & Week 0 & Week 4 & Change (\%) & Week 0 & Week 4 & Change (\%) & & \\
\hline Framingham equation ${ }^{\mathrm{d}, \mathrm{f}}$ & $5.0 \pm 0.8$ & $5.2 \pm 0.8$ & 4 & $5.2 \pm 0.8$ & $3.6 \pm 0.6^{e}$ & -30 & $<0.0001$ & 0.0002 \\
\hline Reynolds score ${ }^{d, g}$ & $6.2 \pm 0.8$ & $6.2 \pm 0.8$ & 1 & $6.3 \pm 0.9$ & $4.1 \pm 0.6^{\mathrm{e}}$ & -35 & $<0.0001$ & $<0.0001$ \\
\hline
\end{tabular}

${ }^{a}$ Values are means \pm SEM.

${ }^{b} P$ value for the comparison of changes after Active diet and Control diet.

${ }^{c} P$ value for the comparison of changes after Active diet and Control diet, after correction for weight change.

${ }^{d}$ The overall effect of diet was significant: $P<0.0001$.

e Significantly different from baseline (Week 0$), P<0.0001$.

${ }^{\mathrm{f}} \mathrm{CHD}$ risk calculated using the Framingham cardiovascular disease predictive equation [41] considering gender, age, total cholesterol, HDL-cholesterol, and smoking habits.

${ }^{9} \mathrm{CHD}$ risk calculated using the Reynolds risk score $[42,43]$ considering gender, age, total cholesterol, HDL-cholesterol, CRP and smoking habits.

reported in dyslipidemic subjects $[4,6,8,45,47]$, no randomized intervention has examined the potential CMD preventive power of a complex functional food array targeting subclinical inflammation. Present results put forward interesting possibilities for this dietary approach.

One characteristic of this study is the healthy condition of the cohort evaluated. The volunteers had no particular diagnosis, beyond being considered at risk for cardiometabolic alterations due to their age $(63.3 \pm 0.8$ y) and BMI $\left(28.5 \pm 0.3 \mathrm{~kg} / \mathrm{m}^{2}\right)$. According to mean baseline values for blood lipids, BP and glucose homeostasis parameters (Table 1), the group represents the healthy segment of the Swedish population in the 50-75 yearold range. This judgment is supported by the fact that $59 \%$ of the volunteers exhibited none of the MetS features evaluated, which contrasts with data from a recent survey of MetS prevalence among 50-60 year olders living in Gothenburg, showing that only $5 \%$ of this population group has no risk factor associated to the syndrome [48].

The AD evaluated here included a cluster of functional concepts selected for their abilities to influence different CMD-associated factors, with emphasis on anti-inflammatory properties. The efficacy of the individual concepts has been documented at various levels including intervention studies with humans. Furthermore, since the concepts influence different aspects of the pathophysiological processes associated with CMD, synergistic interaction between functional agents may occur and facilitate the overall modulation of multiple risk indicators. Thus, the daily dosage of some functional components was set below the amount required for optimal effect when tested separately (Table 3), improving the general palatability of the diet.

CD exhibited a good nutritional profile, which matched the Nordic Nutritional Recommendations. Although its dietary fiber content was lower, the CD contribution approached the current estimated fiber intake for the Swedish population (Swedish Food Administration, Personal Communication). Also, besides being rich in functional ingredients, $A D$ had an improved fat quality (Table 2) and its long-chain $\omega-3$ fatty acid content was 10 times larger than in CD. Both diets were well accepted and tolerated by the participants. The variety of foods encompassed, the inclusion of meat and other animal products and the minor amount of alcoholic drinks allowed favored the high dietary adherence and completion rates recorded.

A somewhat greater weight loss was observed after $\mathrm{AD}$, which agrees with the marked satiating action reported for this diet by most participants, an effect that may be due to its higher dietary fiber and protein contents. In fact, $50 \%$ of the participants were prescribed increased dietary energy after the first 2 weeks on the regime when their weight loss tendency became evident, in contrast to only $25 \%$ requiring that intervention during the CD period. In spite of that a $1.8 \%(1.4 \pm 0.2 \mathrm{~kg})$ mean decrease was recorded after AD. Nonetheless, the statistical adjustment made for the impact of weight variation showed that most of the metabolic improvement observed after $\mathrm{AD}$ was attributable to the dietary modification per se and not to a mere weight loss effect.

Blood lipid and apolipoprotein profiles were practically unaffected by $\mathrm{CD}$ but sharp reductions in triglycerides, total cholesterol, LDL cholesterol as well as in LDL/ HDL and apoB/apoA1 ratios were recorded after the $A D$ period. The latter observation is noteworthy, given the strong association between this quotient and the MetS [49]. The beneficial impact of a low glycemic index diet on blood cholesterol [50] together with the triglyceride-reducing action of polyunsaturated fatty acids from marine origin [10] and content of other known cholesterol-lowering foods and ingredients (soybeans and soy protein, viscous dietary fibers, plant stanols and almonds) are most probably responsible for the overall effect observed with AD.

None of the diets affected insulin sensitivity as estimated by HOMA-IR, although AD promoted slightly higher fasting glucose values than CD. Such an increased glycemia should not pose a risk for healthy 
individuals, a presumption supported by the reduction recorded in $\mathrm{HbA}_{1 \mathrm{c}}$ and unchanged values for fasting FFA.

The minor decrease in $\mathrm{HbA}_{1-\mathrm{c}}$ observed with $\mathrm{AD}$ might be the consequence of modulated glycation rate during the AD period. The diet's low glycemic impact and high phenolic content, both with anti-glycative effects [51,52], may have contributed to this result.

CRP is an indicator of the inflammatory status of recognized importance in relation to cardiometabolic alterations [42,53], with independent predictive value for incident diabetes and cardiovascular diseases [7,54]. The biomarker decreased markedly after $\mathrm{AD}$, with significant difference between diets after adjustment for weight change. It is tempting to speculate that the improved CRP levels may be due to the antinflammatory properties of AD. The CRP-lowering effectivity of a diet enriched in oily fish, blueberries and wholegrain products was recently shown in patients with impaired glucose tolerance [55].

In addition to improving metabolic risk indicators, $\mathrm{AD}$ promoted a significant drop in systolic BP. Such a change may be related, for instance, to the high supply of long chain $\omega-3$ fatty acids, ingredients with suggested BP-modulating activity [56]. Although the present cohort was normotensive (Table 1), the observed pressure reduction resembles that observed with a composite drug treatment in hypertensive volunteers [57].

Besides modulating individual markers associated to CMD, AD also decreased cardiovascular risk as estimated by two different models. The Reynolds algorithm resulted in larger variation from baseline $(-34 \%)$ than the Framingham score $(-30 \%)$, stressing the importance of the CRP reduction promoted by this diet.

The improvement achieved for different biomarkers after AD in this relatively low risk group, compares favorably with other dietary interventions. Most of the investigations on the effect of diet CMD-related parameters have been carried out in patients that have metabolic alterations, such as dyslipidemia. A portfolio of cholesterol-lowering foods reduced LDL cholesterol values by $33 \%$ in a 4-week trial with hypercholesterolemics [5], which is alike the variation recorded here with a normocholesterolemic group. Furthermore, the presently reported impact of $\mathrm{AD}$ on the apoB/Apo $\mathrm{A} 1$ ratio, $\mathrm{CRP}$ concentration and Framinghams CVD risk is comparable to those previously attained in hypercholesterolemics following the cholesterol-lowering portfolio regime $[5,6]$.

Also, the effect of AD on total (-26\%) and LDL cholesterol levels $(-34 \%)$ exceeds those reported for the "Nordic" diet in hypercholesterolemic individuals $(-16 \%$ and $-21 \%$, respectively) a regime that, in contrast to ours, did not affect triglycerides or systolic BP beyond weight-loss effects [8]. The AD also promoted greater
LDL-cholesterol, triglyceride and CRP reductions than Mediterranean-style regimes administered to individuals at high cardiovascular risk [58].

Compared to other dietary interventions performed in healthy volunteers, the action of the AD on different CMD-related variables is also remarkable. Its effects on systolic BP are similar to those of reduced sodium/ DASH [59] or whole-grain [60] regimes. Moreover, in terms of LDL cholesterol reduction $\mathrm{AD}$ appears impressively more effective than vegetarian [61] or low GI [50] regimes. The larger effectiveness of $\mathrm{AD}$ reflects the power of its multifunctional character.

It is relevant noting that the AD effects were observed under conditions aiming to prevent weight changes. In view of the perceived high satiating ability of the diet, larger weight reductions could be expected if it was consumed ad libitum. This potential deserves further investigation, since dietary interventions promoting weight losses of $5 \%$ or more generally result in additional metabolic improvement $[9,62,63]$.

The present study had limitations. An evident constraint is the unbalanced gender participation, since $80 \%$ of the participants were women. Nevertheless, the lower responsiveness of women to treatments targeting metabolic alterations, such as hyperlipidemias [64,65], stresses the relevance of our results. The relative heterogeneity of the cohort regarding metabolic characteristics may also be seen as limiting. However, the group reflects the healthy mature segment of the local population. The study length represents another limitation. Prolonged open interventions often yield inferior results, a pattern influenced by reduced dietary compliance. Nonetheless, the good acceptability recorded for the AD allows expectations for reasonable treatment adherence in longer term trials. An increased availability of active food items and ingredients in the near future may ease the achievement of this goal.

The possible impact of AD on body composition and fat distribution was not evaluated here. Since these factors are importantly associated with cardiometabolic risk $[46,54]$, it would be interesting to include them in future studies on the role of functional diets in the prevention of cardiometabolic alterations. At last, the experimental design envisaged sufficient statistical power regarding changes in LDL cholesterol and CRP but the greater statistical dispersion associated to other biomarkers, such as insulin, PAI-1 and TNF- $\alpha$, may have left the study underpowered to confirm their modification. This should be born in mind when interpreting the non-significant changes recorded in these parameters.

\section{Conclusion}

Tested in a group of middle-aged healthy overweight individuals, a multifunctional diet could modulate 
different CMD-related variables. The beneficial metabolic effects, good acceptability and ease of implementation shown for the diet in this cohort, suggest this type of regime as a promising tool for dietary preventive action against CMD.

\section{Additional material}

Additional file 1: Functional products and ingredients included in the active diet.

Additional file 2: Representative 1-day menus for $A D$ and $C D$.

\section{Abbreviations}

AD: active diet; apoA: apolipoprotein A; Apo B1: apolipoprotein B1; BP: blood pressure; CD: control diet; CMD: cardiometabolic diseases; CRP: C-reactive protein; FFA: free fatty acids; HBA1c: glycated hemoglobin; HDL: high density lipoprotein; hs-CRP: high sensitivity C-reactive protein; HOMA-IR: homeostatic model assessment of insulin resistance; IL-6: interleukin 6; LDL: Iow density lipoprotein; MetS: Metabolic syndrome; PAl-1: plasminogen activator inhibitor 1; TNF-a: tumor necrosis factor alpha.

\section{Acknowledgements}

The authors thank Dr Peter Höglund (Region Skåne Competence Centre for Clinical Research, Lund) for assistance with statistical analyses. This study was funded by the Lund University Antidiabetic Food Center, a VINNOVA VINN Excellence Center (I. Björck).

\section{Author details}

${ }^{1}$ Antidiabetic Food Centre, Lund University, P.O. Box 121, SE-221 00 Lund Sweden. ${ }^{2}$ Department of Applied Nutrition and Food Chemistry, Lund University, SE-221 00 Lund, Sweden. ${ }^{3}$ Primary Health Care Centre, Dalby, Sweden. ${ }^{4}$ ddun Mat och Näringskonsult, Lund, Sweden.

\section{Authors' contributions}

$\mathrm{IB}, \mathrm{JT}$ and $\mathrm{MJ}$ were responsible for the study concept and design; JT, A-M $\AA$ and AN conducted the research; UJ designed the menus; UJ and JT were responsible for the participant's dietetic instruction and coaching; RE was the medical supervisor of the study; JT. and AN analyzed data; JT drafted the manuscript; JT and IB had primary responsibility for final content. All authors revised, discussed and approved the final paper.

\section{Competing interests}

The authors declare that they have no competing interests.

Received: 22 November 2011 Accepted: 2 April 2012

Published: 2 April 2012

\section{References}

1. WHO: The Global Burden of Disease: 2004 Update Gèneve, Switzerland: World Health Organization; 2008.

2. Feldeisen SE, Tucker KL: Nutritional strategies in the prevention and treatment of metabolic syndrome. Appl Physiol Nutr Metab 2007, 32:42-60.

3. Lloyd-Jones DM, Hong Y, Labarthe D, Mozaffarian D, Appel L, Van Horn L, Greenlund K, Daniels S, Nichol G, Tomaselli GF, Arnett DK, Fonarow C, Ho M, Lauer MS, Masoudi FA, Robertson RM, Roger V, Schwamm LH, Sorlie P, Yancy CW, Rosamond WD: Defining and setting national goals for cardiovascular health promotion and disease reduction: The American Heart Association's strategic impact goal through 2020 and beyond. Circulation 2010, 121:586-613.

4. Jenkins DJA, Kendall CWC, Faulkner D, Vidgen E, Trautwein EA, Parker TL, Marchie A, Koumbridis G, Lapsley KG, Josse R, Leiter LA, Connelly PW: A dietary portfolio approach to cholesterol reduction: Combined effects of plant sterols, vegetable proteins, and viscous fibers in hypercholesterolemia. Metabolism 2002, 51:1596-1604.
5. Jenkins DJA, Kendall CWC, Marchie A, Faulkner DA, Josse AR, Wong JM, de Souza R, Emam A, Parker TL, Vidgen E, Trautwein EA, Lapsley KG, Josse RG, Leiter LA, Singer W, Connelly PW: Direct comparison of a dietary portfolio of cholesterol-lowering foods with a statin in hypercholesterolemic participants. Am J Clin Nutr 2005, 81:380-387.

6. Jenkins DJ, Chiavaroli L, Wong JM, Kendall C, Lewis GF, Vidgen E, Connelly PW, Leiter LA, Josse RG, Lamarche B: Adding monounsaturated fatty acids to a dietary portfolio of cholesterol-lowering foods in hypercholesterolemia. Can Med Assoc J 2010, 182:1961-1967.

7. Jenkins DJ, Kendall CW, Marchie A, Faulkner DA, Josse AR, Wong JM, de Souza R, Emam A, Parker TL: Direct comparison of dietary portfolio vs statin on C-reactive protein. Eur J Clin Nutr 2005, 59:851-860.

8. Adamsson V, Reumark A, Fredriksson IB, Hammarström E, Vessby B, Johansson G, Risérus U: Effects of a healthy Nordic diet on cardiovascular risk factors in hypercholesterolaemic subjects: a randomized controlled trial (NORDIET). J Intern Med 2011, 269:150-159.

9. O'Keefe $\mathrm{JH}$, Gheewala NM, O'Keefe JO: Dietary strategies for improving post-prandial glucose, lipids, inflammation and cardiovascular health. $J$ Am Coll Cardiol 2008, 51:249-255.

10. Lopez-Alvarenga JC, Ebbesson SOE, Ebbesson LO, Tejero M, Vorugantia S, Comuzzie AG: Polyunsaturated fatty acids effect on serum triglycerides concentration in the presence of metabolic syndrome components. The Alaska-Siberia Project. Metabolism 2010, 59:86-92.

11. Bruce KD, Hanson MA: The developmental origins, mechanisms and implications of metabolic syndrome. J Nutr 2010, 140:648-652.

12. Expert Panel on Detection, and Treatment of High Blood Cholesterol in Adults: Third report of the national cholesterol education program (NCEP) expert panel on detection, evaluation, and treatment of high blood cholesterol in adults (adult treatment panel III) final report. Circulation 2002, 106:3143-3421.

13. Giugliano D, Ceriello A, Esposito K: The effects of diet on inflammation Emphasis on the metabolic syndrome. J Am Coll Cardiol 2006, 48:677-685.

14. Leeman M, Ostman E, Bjorck I: Vinegar dressing and cold storage of potatoes lowers postprandial glycaemic and insulinaemic responses in healthy subjects. Eur J Clin Nutr 2005, 59:1266-1271.

15. Nilsson M, Holst JJ, Bjorck IME: Metabolic effects of amino acid mixtures and whey protein in healthy subjects: studies using glucose-equivalent drinks. Am J Clin Nutr 2007, 85:996-1004.

16. Valtuena S, Pellegrini N, Franzini L, Bianchi MA, Ardigò D, Del Rio D, Piatti P, Scazzina F, Zavaroni I, Brighenti F: Food selection based on total antioxidant capacity can modify antioxidant intake, systemic inflammation, and liver function without altering markers of oxidative stress. Am J Clin Nutr 2008, 87:1290-1297.

17. Calder PC: $n-3$ polyunsaturated fatty acids, inflammation, and inflammatory diseases. Am J Clin Nutr 2006, 83(Suppl 6):1505S-1519S.

18. Osman N, Adawi D, Ahrne S, Jeppsson B, Molin G: Endotoxin- and Dgalactosamine-induced liver injury improved by the administration of Lactobacillus, Bifidobacterium and blueberry. Dig Liver Dis 2007, 39:849-856.

19. Mitsou EK, Panopoulou N, Turunen K, Spiliotis V, Kyriacou A: Prebiotic potential of barley derived beta-glucan at low intake levels: A randomised, double-blinded, placebo-controlled clinical study. Food Res Int 2010, 43:1086-1092.

20. Nilsson A, Ostman E, Preston T, Björck I: Effects of GI vs content of cereal fibre of the evening meal on glucose tolerance at a subsequent standardized breakfast. Eur J Clin Nutr Nutr 2008, 62:712-720.

21. Nilsson AC, Ostman EM, Holst JJ, Björck IM: Including indigestible carbohydrates in the evening meal of healthy subjects improves glucose tolerance, lowers inflammatory markers, and increases satiety after a subsequent standardized breakfast. J Nutr 2008, 138:732-739.

22. Nordic Council of Ministers: Nutrition Recommendations 2004: integrating nutrition and physical activity. 4 edition. Copenhagen: Nordic Council of Ministers; 2004.

23. Kaliora AC, Dedoussis GVZ: Natural antioxidant compounds in risk factors for CVD. Pharmacol Res 2007, 56:99-109.

24. Erlund I, Koli R, Alfthan G, Marniemi J, Puukka P, Mustonen P, Mattila P, Jula A: Favorable effects of berry consumption on platelet function, blood pressure, and HDL cholesterol. Am J Clin Nutr 2008, 87:323-331.

25. Dugoua JJ, Seely D, Perri D, Cooley K, Forelli T, Mills E, Koren G: From type 2 diabetes to antioxidant activity: a systematic review of the safety and 
efficacy of common and cassia cinnamon bark. Can J Physiol Pharmacol 2007, 85:837-847.

26. Musa-Veloso K, Binns MA, Kocenas AC, Poon T, Elliot JA, Rice H, OppedalOlsen $\mathrm{H}$, Lloyd H, Lemke S: Long-chain omega-3 fatty acids eicosapentaenoic acid and docosahexaenoic acid dose-dependently reduce fasting serum triglycerides. Nutr Rev 2010, 68:155-167.

27. McKeown NM, Meigs JB, Liu S, Saltzman E, Wilson PW, Jacques PF: Carbohydrate nutrition, insulin resistance, and the prevalence of the metabolic syndrome in the Framingham Offspring Cohort. Diabetes Care 2004, 27:538-546.

28. Barclay A, Petocz P, McMillan-Price J, Flood V, Prvan T, Mitchell P, BrandMiller J: Glycemic index, glycemic load and diabetes risk: a meta-analysis. Diabetes Res Clin Pract 2008, 79(Suppl 1):S30-S31.

29. Ceriello A, Davidson J, Hanefeld M, Leiter L, Monnier L, Owens D, Tajima N, Tuomilehto J: Postprandial hyperglycaemia and cardiovascular complications of diabetes: an update. Nutr Metab Cardiovasc Dis 2006, 16:453-456.

30. Azadbakht L, Kimiagar M, Mehrabi Y, Esmaillzadeh A, Padyab M, Hu FB, Willett WC: Soy inclusion in the diet improves features of the metabolic syndrome: a randomized crossover study in postmenopausal women. Am J Clin Nutr 2007, 85:735-741.

31. Derdemezis CS, Filippatos TD, Mikhailidis DP: Effects of plant sterols and stanols beyond low-density lipoprotein cholesterol lowering. I Cardiovasc Pharmacol Ther 2010, 15:120-314.

32. Griel AE, Kris-Etherton PM: Tree nuts and the lipid profile: a review of clinical studies. Br J Nutr 2006, 96(Suppl 2):S68-S78.

33. Azadbakht L, Kimiagar M, Mehrabi Y, Esmaillzadeh A, Hu FB, Willett WC: Soy consumption, markers of inflammation, and endothelial function: a cross-over study in postmenopausal women with the metabolic syndrome. Diabetes Care 2007, 30:967-973.

34. Azadbakht L, Esmaillzadeh A: Soy and cardio-metabolic abnormalities: an update. J Res Med Sci 2008, 13:88-96.

35. Nagarajan S: Mechanisms of anti-atherosclerotic functions of soy-based diets. J Nutr Biochem 2010, 21:255-260.

36. Basu A, Du M, Leyva MJ, Sanchez K, Betts NM, Wu M, Aston CE, Lyons TJ: Blueberries decrease cardiovascular risk factors in obese men and women with metabolic syndrome. J Nutr 2010, 140:1582-1587.

37. Lomax AR, Calder PC: Probiotics, immune function, infection and inflammation: A review of the evidence from studies conducted in humans. Curr Pharm Des 2009, 15:1428-1518.

38. Ooi LG, Liong MT: Cholesterol-lowering effects of probiotics and prebiotics: a review of in vivo and in vitro findings. Int J Mol Sci 2010, 11:2499-2522

39. Friedewald WT, Levy Rl, Fredriksson DS: Estimation of the concentration of low-density lipoprotein cholesterol in plasma, without use of the preparative ultracentrifuge. Clin Chem 1972, 18:499-502.

40. Matthews DR, Hosker JP, Rudenski AS, Naylor BA, Treacher DF, Turner RC: Homeostasis model assessment: insulin resistance and beta-cell function from fasting plasma glucose and insulin concentrations in man. Diabetologia 1985, 28:412-419.

41. Anderson KM, Wilson PWF, Odell PM, Kannel WB: An updated coronary risk profile -a statement for health-professionals. Circulation 1991, 83:356-362.

42. Ridker PM, Buring JE, Rifai N, Cook NR: Development and validation of improved algorithms for the assessment of global cardiovascular risk in women - The Reynolds Risk Score. JAMA 2007, 297:611-619.

43. Ridker PM, Paynter NP, Rifai N, Gaziano JM, Cook NR: C-Reactive Protein and parental history improve global cardiovascular risk prediction: The Reynolds Risk Score for men. Circulation 2008, 118:2243-2251.

44. Hulthe J, Fagerberg B: Circulating oxidized LDL is associated with subclinical atherosclerosis development and inflammatory cytokines (AIR Study). Arterioscler Thromb Vasc Biol 2002, 22:1162-1167.

45. King DE, Egan BM, Woolson RF, Mainous A III, Al-Solaiman Y, Jesri A: Effect of a high-fiber diet vs a fiber-supplemented diet on C-reactive protein level. Arch Intern Med 2007, 167:502-506.

46. Alberti KG, Eckel RH, Grundy SM, Zimmet PZ, Cleeman Jl, Donato KA, Fruchart JC, James WP, Loria CM, Smith SC Jr: Harmonizing the metabolic syndrome: a joint interim statement of the International Diabetes Federation Task Force on Epidemiology and Prevention; National Heart, Lung, and Blood Institute; American Heart Association; World Heart
Federation; International Atherosclerosis Society; and International Association for the Study of Obesity. Circulation 2009, 120:1640-1645.

47. Esposito K, Ciotola M, Giugliano D: Mediterranean diet and the metabolic syndrome. Mol Nutr Food Res 2007, 51:1268-1274.

48. Welin L, Adlerberth A, Caidahl K, Eriksson H, Hansson PO, Johansson S, Rosengren A, Svärdsudd K, Welin C, Wilhelmsen L: Prevalence of cardiovascular risk factors and the metabolic syndrome in middle-aged men and women in Gothenburg, Sweden. BMC Public Health 2008, 8:403.

49. Sierra-Johnson J, Somers VK, Kuniyoshi FHS, Garza CA, Isley WL, Gami AS, Lopez-Jimenez F: Comparison of apolipoprotein-B/apolipoprotein-A1 in subjects with versus without the metabolic syndrome. Am J Cardiol 2006, 98:1369-1373.

50. de Rougemont A, Normand S, Nazare JA, Skilton MR, Sothier M, Vinoy S, Laville M: Beneficial effects of a 5-week low-glycaemic index regimen on weight control and cardiovascular risk factors in overweight nondiabetic subjects. Br J Nutr 2007, 98:1288-1298.

51. Jenkins DJ, Wolever TM, Buckley G, Lam KY, Giudici S, Kalmusky J, Jenkins AL, Patten RL, Bird J, et al: Low-glycemic-index starchy foods in the diabetic diet. Am J Clin Nutr 1988, 48:248-254.

52. Verzelloni E, Pellacani C, Tagliazucchi D, Tagliaferri S, Calani L, Costa LG, Brighenti F, Borges G, Crozier A, Conte A, Del Rio D: Antiglycative and neuroprotective activity of colon-derived polyphenol catabolites. Mol Nutr Food Res 2011, 55(Suppl 1):S35-S43.

53. Eckel RH, Grundy SM, Zimmet PZ: The metabolic syndrome. Lancet 2005 , 365:1415-1428.

54. Ridker PM, Hennekens $\mathrm{CH}$, Buring JE, Rifai N: C reactive protein and other markers of inflammation in the prediction of cardiovascular disease in women. N Engl J Med 2000, 342:836-843.

55. de Mello VDF, Schwab U, Kolemainen M, Koenig W, Siloaho M, Poutanen K, Mykkänen $H$, Uusitupa M: A diet high in fatty fish, bilberries and wholegrain products improves markers of endothelial function and inflammation in individuals with impaired glucose metabolism in a randomized controlled trial: The Sysdimet study. Diabetologia 2011, 54:2755-2767.

56. Morris MC, Sacks F, Rosner B: Does fish-oil lower blood pressure? A metanalysis of controlled trials. Circulation 1993, 88:523-533.

57. Jamerson K, Weber MA, Bakris GL, Dahlöf B, Pitt B, Shi V, Hester A, Gupte J, Gatlin M, Velazquez EJ: Benazepril plus Amlodipine or Hydrochlorothiazide for hypertension in high-risk patients. N Engl J Med 2008, 359:2417-2428

58. Estruch R, Martínez-González MA, Corella D, Salas-Salvadó J, Ruiz-Gutiérrez V, Covas MI, Fiol M, Gómez-Gracia E, López-Sabater MC, Vinyoles E, Arós F, Conde M, Lahoz C, Lapetra J, Sáez G, Ros E, the PREDIMED Study investigators: Effects of a Mediterranean-style diet on cardiovascular risk factors: a randomized trial. Ann Intern Med 2006, 145:1-11.

59. Sacks FM, Svetkey LP, Vollmer WM, Appel L, Bray GA, Harsha D, Obarzanek E, Conlin PR, Miller ER, Simons-Morton DG, Karanja N, Lin PH, DASH-Sodium Collaborative Research Group: Effects on blood pressure of reduced dietary sodium and the Dietary Approaches to Stop Hypertension (DASH) diet. N Engl I Med 2001, 344:3-10.

60. Tighe P, Duthie G, Vaughan N, Brittenden J, Simpson WG, Duthie S, Mutch W, Wahle K, Horgan G, Thies F: Effect of increased consumption of whole-grain foods on blood pressure and other cardiovascular risk markers in healthy middle-aged persons: a randomized controlled trial. Am J Clin Nutr 2010, 92:733-740.

61. Barnard ND, Scialli AR, Bertron P, Hurlock D, Edmonds K, Talev L: Effectiveness of a low-fat vegetarian diet in altering serum lipids in healthy premenopausal women. Am J Cardiol 2000, 85:969-972.

62. Azadbakht L, Mirmiran P, Esmaillzadeh A, Azizi T, Azizi F: Beneficial effects of a Dietary Approaches to Stop Hypertension eating plan on features of the metabolic syndrome. Diabetes Care 2005, 28:2823-2831.

63. Dagogo-Jack S, Egbuonu N, Edeoga C: Principles and practice of nonpharmacological interventions to reduce cardiometabolic risk. Med Princ Pract 2010, 19:167-175.

64. Mehner A, Lindblad U, Råstam L, Boström KB: Cholesterol in women at high cardiovascular risk is less successfully treated than in corresponding men. The Skaraborg Hypertension and Diabetes Project. Eur J Clin Pharmacol 2008, 64:815-820.

65. Santos RD, Waters DD, Tarasenko L, Messig M, Jukema JW, Ferrières J, Verdejo J, Chiang CW, L-TAP 2 Investigators: Low- and high-density 
lipoprotein cholesterol goal attainment in dyslipidemic women: The

Lipid Treatment Assessment Project (L-TAP) 2. Am Heart J 2009,

158:860-866.

doi:10.1186/1743-7075-9-29

Cite this article as: Tovar et al.: A diet based on multiple functional

concepts improves cardiometabolic risk parameters in healthy subjects.

Nutrition \& Metabolism 2012 9:29.

Submit your next manuscript to BioMed Central and take full advantage of:

- Convenient online submission

- Thorough peer review

- No space constraints or color figure charges

- Immediate publication on acceptance

- Inclusion in PubMed, CAS, Scopus and Google Scholar

- Research which is freely available for redistribution

Submit your manuscript at 